\title{
Bronchial Kaposi's sarcoma after single lung transplantation
}

\author{
C. Sleiman, H. Mal, C. Roué, O. Groussard, P. Baldeyrou, P. Olivier, \\ M. Fournier, R. Pariente
}

\begin{abstract}
Bronchial Kaposi's sarcoma after single lung transplantation. C. Sleiman, H. Mal, C. Roué, O. Groussard, P. Baldeyrou, P. Olivier, M. Fournier, R. Pariente. @ERS Journals Ltd 1997.

ABSTRACT: Kaposi's sarcoma (KS) has been reported in $6 \%$ of malignancies of solid organ transplant recipients. Most of the observations have been in recipients of renal allografts but, so far, KS has not been described in lung transplantation.

We report a case of bronchial KS occurring in a black patient 6 months after single lung-transplantation. Skin lesions were absent and, interestingly, KS lesions were observed solely in the trachea and the native lung.

Following reduction of the immunosuppressive regimen a complete remission was obtained 1 year later. Up to the present time, this clinical remission is very encouraging, but close surveillance remains necessary to detect rejection episodes or the reappearance of $\mathrm{KS}$ following manipulation of the immunosuppressive
\end{abstract} therapy.

Eur Respir J 1997; 10: 1181-1183.
Service de Pneumologie et Réanimation Respiratoire and Service de Cytologie et d'Anatomie Pathologique, Hôpital Beaujon, Clichy, France.

Correspondence: C. Sleiman

Service de Pneumologie et Réanimation Hôpital Beaujon

100 avenue du Général Leclerc

92110 Clichy

France

Keywords: Cancer, immunosuppression, Kaposi's sarcoma, lung transplantation

Received: October 281996

Accepted after revision January 241997
Recipients of solid organ transplants are prone to develop a variety of malignant tumours whilst under longterm immunosuppression [1-4]. Among these tumours, Kaposi's sarcoma (KS) has been reported in $6 \%$ of neoplasms of transplant recipients in the Cincinnati Transplant Tumor Registry [1]. Epidemiological data have shown that the incidence of KS in the renal transplant population is increased 400-500 fold over the general population of the same ethnic group [5]. Most of the reported experience of KS has been in renal transplantation but, so far, no case of KS has been described in recipients of lung allografts. We report a case of bronchial KS occurring in the native lung after single lung transplantation.

\section{Case report}

A 56 year old black man from Guinea underwent a single left lung transplantation at our centre in June 1992 because of end-stage chronic obstructive pulmonary disease (COPD). The donor was a 26 year old man, who had sustained a fatal head injury and who fulfilled the criteria for lung donor status [6]. The patient tolerated the procedure well and was extubated on the day after transplantation. Initial postoperative immunosuppressive therapy included cyclosporin, azathioprine and antilymphocyte globulin. The dose of cyclosporin was adjusted to maintain whole-blood levels at $200-250 \mathrm{ng} \cdot \mathrm{mL}^{-1}$ (radioimmunoassay method). Azathioprine was given at a daily dose of $2 \mathrm{mg} \cdot \mathrm{kg}^{-1}$, in order to keep the total white cell count above 4,000 cells $\cdot \mathrm{mm}^{-1}$. Antilymphocyte globulin was discontinued after 5 days. Methylprednisolone $(500 \mathrm{mg})$ was given intravenously on the first postoperative day. Orally administered prednisolone $(0.5$ $\mathrm{mg} \cdot \mathrm{kg}^{-1} \cdot$ day $^{-1}$ in decreasing doses) was initiated on posttransplant day 30 .

The postoperative course was marked by two episodes of allograft rejection occurring on postoperative days 12 and 35 , and a cytomegalovirus (CMV) pneumonia on postoperative day 28 , successfully treated by ganciclovir. During acute rejection episodes, immunosuppression was augmented with intravenously administered methylprednisolone $1 \mathrm{~g} \cdot \mathrm{day}^{-1}$ for three consecutive days, followed by oral prednisolone $1 \mathrm{mg} \cdot \mathrm{kg}^{-1} \cdot \mathrm{day}^{-1}$ in decreasing doses to $10 \mathrm{mg} \cdot \mathrm{day}^{-1}$. The patient was discharged from the hospital on postoperative day 50 and has progressed to vigorous physical activity, including bicycle riding.

Six months following transplantation, the patient presented with a low grade fever, dry cough and breathlessness. Physical examination was significant only for diminished breath sound at the native lung. Cutaneous examination was notable for the absence of skin lesions. Body temperature was $38^{\circ} \mathrm{C}$, with a respiratory rate of 22 breaths $\cdot \mathrm{min}^{-1}$. Arterial blood gas analysis showed a $\mathrm{pH}$ value of 7.42, an arterial carbon dioxide tension $\left(\mathrm{Pa}, \mathrm{CO}_{2}\right)$ of $3.9 \mathrm{kPa}$, and an arterial oxygen tension $\left(\mathrm{Pa}, \mathrm{O}_{2}\right)$ of $8.1 \mathrm{kPa}$ (with the patient breathing room air). A chest radiograph revealed an emphysematous native lung, with a normal transplanted left lung.

Lung rejection and/or infection were suspected and the patient underwent a diagnostic flexible bronchoscopy. Bronchoscopic inspection of the trachea and the airways demonstrated small, purpuric papular lesions distributed throughout the trachea and the right middle lobe bronchus on the native lung. All these lesions involved the surface of the bronchial wall, slightly raised without any bronchial obstruction. No lesion was noted 
on the transplanted lung. Biopsies of the lesions of the native lung were performed, together with transbronchial biopsy and bronchoalveolar lavage (BAL) of the transplanted lung. Because of excessive bleeding after the bronchial lesions were biopsied, only three specimens were obtained. Transbronchial biopsies revealed intranuclear and intracytoplasmic inclusions characteristic of CMV, without evidence of acute rejection. Culture of BAL cells was positive for CMV. Endobronchial biopsy specimens of the purpuric lesions of the native lung were consistent with $\mathrm{KS}$, microscopically showing the typical features of $\mathrm{KS}$, with the presence of numerous spindle-shaped cells with irregular cleft-like spaces. The patient was then tested for human immunodeficiency virus (HIV), and was found to be HIV-negative.

In view of these findings, the diagnosis of CMV pneumonia associated with bronchial KS was made. Cytomegalovirus infection was treated with ganciclovir (for 21 days) and immunosuppressive therapy was reduced by cessation of azathioprine administration. Only cyclosporin and prednisolone $\left(10 \mathrm{mg} \cdot \mathrm{day}^{-1}\right)$ were maintained. Computed tomography (CT) scans of the chest and abdomen, and upper and lower gastrointestinal endoscopy were performed to exclude any other internal visceral involvement. All these examinations were normal.

Within 14 days of the initiation of ganciclovir treatment, the patient showed evidence of clinical improvement, including the disappearance of fever, resolution of hypoxaemia and tachypnoea, and improved exercise tolerance. He was discharged from the hospital 25 days after the start of treatment.

In the year following the demonstration of $\mathrm{KS}$, whilst the patient was maintained on cyclosporin and prednisolone $\left(10 \mathrm{mg} \cdot \mathrm{day}^{-1}\right)$, he presented three episodes of acute rejection confirmed by transbronchial biopsy and treated by $1 \mathrm{~g}$ of methylprednisolone on three consecutive days. At each episode, flexible bronchoscopy revealed the same aspect and profile of the KS lesions of the native lung.

In January 1994, 12 months after the cessation of azathioprine, a routine bronchoscopy showed spontaneous regression of all tracheal and bronchial lesions. Bronchial biopsies at the previous sites of the KS lesions were normal. Repeated flexible bronchoscopy and CT of the lung showed normal appearances. At the present time, the patient remains well 48 months postoperatively, with a normal lifestyle, and there is no evidence of reappearance of Kaposi's lesions at any site.

\section{Discussion}

In solid organ transplantation, most observations of KS have been in recipients of renal allografts, with few data regarding patients with cardiac or liver allografts $[7,8]$. To our knowledge, KS complicating the course of lung transplantation in HIV-negative patients has not been described.

Kaposi's sarcoma appeared very soon after transplantation ( 6 months) in the present patient, while an average of 22 months is noted in the Cincinnati Transplant Tumor Registry [1]. However, a 6 month delay for appearance of KS has been described by Bismuth et al. [9] in liver transplantation.
Many studies have suggested an infectious agent as the cause of KS. In a report of 20 cases of KS in organ transplant recipients, PENN [2] noted that at least 30\% of the recipients had herpes simplex infections prior to the appearance of KS, and deoxyribonucleic acid (DNA) sequences of human herpesvirus-8 (HHV-8) have been identified in acquired immune deficiency syndrome (AIDS)-associated KS [10-13]. Unfortunately, our patient has not been tested for HHV-8, which has now been clearly associated with the pathogenesis of KS [12]. It is interesting to note that, in our patient, ongoing CMV infection was noted on postoperative day 28 and at onset of KS. This suggests that CMV infection may have led to reactivation of $\mathrm{HHV}-8$, thus indirectly contributing to the development of KS.

Data from the nontransplant literature indicate that there is a strong genetic predisposition to the development of KS, with an increased incidence of certain human leucocyte antigen (HLA) phenotypes in patients with KS: A-19, A-23, B-49 and DR-5 [14-16]. However, these antigens were not present in the present patient. In the Cincinnati Transplant Tumor Registry, a study of HLA typing in 67 transplant recipients with KS showed that any link between developing KS after transplantation and the HLA locus was very weak when the patient's ethnic backgrounds were taken into consideration $[1,14]$.

The occurrence of KS in the absence of skin manifestations is extremely rare [3]. Skin lesions were absent in our patient, and KS lesions were observed solely in the trachea and the native lung. Patient's racial or geographical origins have been linked with onset of KS [2, $3,8]$. In the European study of KS in organ transplants recipients [8], KS was observed in recipients from Central Europe (12\%), the Mediterranean region (47\%), and among black Africans (24\%). The present patient is black African and his donor was a white European man. Because $\mathrm{KS}$ is more common among blacks in Africa, one might hypothesize that ethnic factors may be important in the aetiology of this entity and may explain, in this patient, the absence of KS lesions in the allograft.

A complete remission following reduction of the immunosuppressive regimen by cessation of azathioprine administration was obtained in the present patient. This favourable response has been noted in previous studies [1, 2, 9, 5, 17-19], and provides further evidence of an aetiological role of depressed immunity in the development of KS in association with other important pathogenic factors, such as viruses, genetic or racial factors [3]. In this patient, the clinical remission is so far very encouraging. However, close surveillance remains necessary to detect rejection episodes or the reappearance of Kaposi's sarcoma following manipulation of the immunosuppressive therapy.

\section{References}

1. Penn I. Sarcomas in organ allograft recipients. Transplantation 1995; 12: 1485-1490.

2. Penn I. Kaposi's sarcoma in organ transplant recipients. Transplantation 1979; 27: 8-11.

3. Penn I. Kaposi's sarcoma in immunosuppressed patients. Clin Lab Immunol 1983; 12: 1-10.

4. Penn I. Malignancy. Surg Clin North Am 1994; 74: 1247-1253. 
5. Harwood AR, Osoba D, Goldstein MB, et al. Kaposi's sarcoma in recipients of renal transplants. Am J Med 1979; 67: 759-765.

6. Kendall SWH, Wallwork J. Heart-lung transplantation: indications and technique. Semin Thorac Cardiovasc Surg 1992; 4: 101-106.

7. Penn I. Kaposi's sarcoma. Etiology: immunodeficiency. In: Ziegler JL, Dorfman RF, eds. Kaposi's Sarcoma: Pathophysiology and Clinical Management. New York, Dekker, 1988; pp. 129-150.

8. Farge D, and the Collaborative Transplantation Research Group of Ile de France. Kaposi's sarcoma in organ transplant recipients. Eur J Med 1993; 2: 339-343.

9. Bismuth H, Samuel D, Venancie PY, Menouar G, Szekely AM. Development of Kaposi's sarcoma in liver transplant recipients: characteristics, management and outcome. Transplant Proc 1991; 23: 1438-1439.

10. Moore PS, Chang Y. Detection of herpesvirus-like DNA sequences in Kaposi's sarcoma in patients with and those without HIV infection. N Engl J Med 1995; 332: 11811185.

11. Huang YQ, Li JJ, Kaplan MH, et al Human herpesviruslike nucleic acid in various forms of Kaposi's sarcoma. Lancet 1995; 345: 759-761.

12. Gao SJ, Kingsley L, Hoover DR, et al. Seroconversion to antibodies against Kaposi's sarcoma-associated herpesvirus-related latent nuclear antigens before the development of Kaposi's sarcoma. N Engl J Med 1996; 335: 233-241.

13. Huang YQ, Li JJ, Zhang WG, Feiner D, Friedman-Kien AE. Transcription of human herpesvirus-like agent (HHV8) in Kaposi's sarcoma. J Clin Invest 1996; 97: $2803-$ 2806.

14. Brunson ME, Balakrishnan K, Penn I. HLA and Kaposi's sarcoma in solid organ transplantation. Hum Immunol 1990; 29: 56-63.

15. Berner S, Krakowski A, Schewach-Millet M, Ronen M, Orgad S, Gazit E. Increased frequency of HLA-Aw 19 in Kaposi's sarcoma. Tissue Antigens 1982; 19: 392-396.

16. Prince HE, Schroff RW, Ayoub G, Han S, Gottlieb MS, Fahey JL. HLA studies in acquired immune deficiency syndrome: patients with Kaposi's sarcoma. J Clin Immunol 1984; 4: 1984-1986.

17. Gunawrdena KA, Al-Hasani MK, Haleem A, Al-Suleiman M, Al-Khader A. Pulmonary Kaposi's sarcoma in two recipients of renal transplants. Thorax 1988; 43: 653-656.

18. Montagnino G, Bencini PL, Tarantino A, Ponticelli C. Clinical features and course of Kaposi's sarcoma in kidney transplant patients: report of 13 cases. Am J Nephrol 1994; 41: 121-126.

19. Qunibi W, Akhtar M, Shet K, Earl Ginn H, Devol EB, Taher S. Kaposi's sarcoma: the most common tumor after renal transplantation in Saudi Arabia. Am J Med 1988; 84: 225-232. 